\title{
ON THE INFLUENCE OF APPLIED FIELDS ON SPINEL FORMATION
}

C. KORTE, J.K. FARRER, N. RAVISHANKAR, J. R. MICHAEL ${ }^{1}$, J., SCHMALZRIED ${ }^{2}$ AND . C.B. CARTER

Department of Chemical Engineering and Material Science, University of Minnesota

421 Washington Ave. SE, Minneapolis, MN 55455

' Sandia National Laboratory, Albuquerque, NM 87185-1405

${ }^{2}$ Institut für Physikalische Chemie und Elektrochemie der Universität Hannover

Callinstr. 3-3A, 30167 Hannover, Germany

\section{ABSTRACT}

Interfaces play an important role in determining the effect of electric fields on the mechanism of the formation spinel by solid-state reaction. The reaction occurs by the movement of phase boundaries but the rate of this movement can be affected by grain boundaries in the reactants or in the reaction product. Only by understanding these relationships will it be possible to engineer their behavior. As a particular example of such a study, $\mathrm{MgIn}_{2} \mathrm{O}_{4}$ can be formed by the reaction between single-crystal $\mathrm{MgO}$ substrate and a thin film of $\mathrm{In}_{2} \mathrm{O}_{3}$ with or without an applied electric field. High-resolution backscattered electron (BSE) imaging and electron backscattered diffraction (EBSD) in a scanning electron microscope (SEM) has been used to obtain complementary chemical and crystallographic information.

\section{INTRODUCTION}

Composite ceramics or coated ceramics are materials of great technological importance. The interfacial reactions that take place at elevated temperatures in these materials may lead to a mechanical and/or electrical failure. In cases where the composite material is used as an insulator, it may also be subjected to high electric fields. The presence of an electric field significantly increases ionic transport, thus leading to higher rate of interfacial reactions. This effect is particularly important along interfaces where the rate of matter transport is much higher than that through the bulk.

The formation of a spinel by the reaction between two oxides is a heterogeneous solidstate reaction $[1,2]$. The spinel-forming reaction is important from a technological point of view and also serves as a model reaction system. This reaction can proceed via numerous different mechanisms [1]. If there is no transport of oxygen via the gas phase, the reaction proceeds via the couterdiffusion of cations. The kinetics can be either interface-controlled or diffusioncontrolled [1-6]. The formation of $\mathrm{NiAl}_{2} \mathrm{O}_{4}, \mathrm{MgFe}_{2} \mathrm{O}_{4}$ and $\mathrm{MgIn}_{2} \mathrm{O}_{4}$ spinels has been previously studied $[3,4,7-10]$. The kinetics of the formation of $\mathrm{NiAl}_{2} \mathrm{O}_{4}$ spinel by the reaction between $\mathrm{NiO}$ and different single-crystal substrates of $\mathrm{Al}_{2} \mathrm{O}_{3}$ has been determined using a thin-film approach $[3,4]$. The effect of an applied electric field on the formation of $\mathrm{MgFe}_{2} \mathrm{O}_{4}$ and $\mathrm{MgIn}_{2} \mathrm{O}_{4}$ has been investigated [7-9]. The kinetics of the reaction has been shown to be enhanced for the reactions in the presence of an applied field. The use of Pt markers has been shown to be very effective to mark the position of the interface $[8,9]$. This use of markers lends valuable insight into the reactions that take place in the presence of an electric field as opposed to without such a field.

In the present paper, the influence of an electric field on the reaction between $\mathrm{MgO}$ and $\mathrm{In}_{2} \mathrm{O}_{3}$ to form the $\mathrm{MgIn}_{2} \mathrm{O}_{4}$ spinel is investigated. A thin-film approach has been shown to be very useful in the study of the solid-state reactions under an applied field. High-resolution BSE imaging is combined with EBSD to obtain complementary chemical and crystallographic 


\section{DISCLAIMER}

This report was prepared as an account of work sponsored by an agency of the United States Government. Neither the United States Government nor any agency thereof, nor any of their employees, make any warranty, express or implied, or assumes any legal liability or responsibility for the accuracy, completeness, or usefulness of any information, apparatus, product, or process disclosed, or represents that its use would not infringe privately owned rights. Reference herein to any specific commercial product, process, or service by trade name, trademark, manufacturer, or otherwise does not necessarily constitute or imply its endorsement, recommendation, or favoring by the United States Government or any agency thereof. The views and opinions of authors expressed herein do not necessarily state or reflect those of the United States Government or any agency thereof. 


\section{DISCLAIMER}

\section{Portions of this document may be illegible}

in electronic image products. Images are produced from the best available original document. 
information. The use of EBSP has been shown to be very useful in determining the crystallogaphic aspects of thin-film reactions [11].

\section{EXPERIMENTAL PROCEDURE}

Indium oxide was deposited by pulsed-laser deposition (PLD) onto a cleaved $\mathrm{MgO}(001)$ substrate. The substrate temperature was maintained at $500^{\circ} \mathrm{C}$. The thickness of the $\operatorname{In}_{2} \mathrm{O}_{3}$ layer was about $1-2 \mu \mathrm{m}$. The $\mathrm{MgO}$ substrate contained Pt markers which were produced by solid-state dewetting of a thin $(\sim 2 \mathrm{~nm})$ film on the cleaved substrate. The Pt markers serve to mark the initial position of the interface. In the first sample (sample $A$ ) the reaction between the layers took place at a temperature of $1350^{\circ} \mathrm{C}$ under an applied voltage of $200 \mathrm{~V}$ for 12 minutes with the $\mathrm{MgO}$ substrate in contact with the anode and the $\mathrm{In}_{2} \mathrm{O}_{3}$ film in contact with the cathode. In the second sample (sample B) the reaction was allowed to continue at $1350^{\circ} \mathrm{C}$ for 30 minutes under the applied field.

Cross sections of the samples were then polished using the tripod-polishing technique. Microstructural investigation was carried out using a field-emission SEM (Hitachi S900). The cross-section samples were coated with $2 \mathrm{~nm}$ of Pt to minimize charging. A large difference in the atomic number between the two cations in the spinel makes it an ideal system for investigation using the BSE imaging in the SEM.

EBSD was performed using a JEOL JSM $6400 \mathrm{XV}$ operating at $20 \mathrm{kV}$ with a LaB

filament. The EBSD detector is made up of a 2.5-inch diameter YAG single crystal, $60 \mu \mathrm{m}$ thick, which is epoxied to a fiber optic, 2.5 to 1 inch reducer. The reducer is then coupled to a slowscan CCD camera, which is cooled to below $-10^{\circ} \mathrm{C}$. Elemental information was obtained using an energy-dispersive X-ray spectrometry (EDS) system that is also attached to this SEM. The patterns were analyzed by using a Hough transform to locate bands and band edges in the pattern. This crystallographic information, along with the elemental information, is then used to access possible phases through the database of powder diffraction files [12]. The appropriate phase is then selected and an indexed, simulated pattern is created to compare with the original and to give the orientation information.[12].

\section{RESULTS AND DISCUSSION}

The deposition of $\mathrm{In}_{2} \mathrm{O}_{3}$ on $\mathrm{MgO}$ substrate at $500^{\circ} \mathrm{C}$ results in the formation of a polycrystalline film. A plan-view secondary-electron image of the film after annealing is shown in Fig.1. The grain size of the film is comparable to the film thickness leading to the formation of columnar grains of $\operatorname{In}_{2} \mathrm{O}_{3}$ on the substrate. In such a situation the grain boundaries in the film play an important role in controlling the reaction. A BSE image in cross-section of sample A is shown in Fig.2. The spinel reaction product (with an intermediate BSE contrast) is seen to form at the interface between $\mathrm{MgO}$ (dark) and $\operatorname{In}_{2} \mathrm{O}_{3}$ (bright). A portion of the $\mathrm{Pt}$ electrode is seen on the top of the image. At this temperature and time, the reaction has only partially taken place. The $\mathrm{Pt}$ markers (bright spots) are seen to remain in the $\mathrm{MgO}$ substrate. In the absence of an applied, it has been reported that the $\mathrm{Pt}$ markers are located in the spinel layer [8, 9]. However, in the presence of a field, in addition to the counterdiffusion of the cations, there is a superposed flux of cations towards the negative electrode, which leads to a shift of the reaction layer towards the cathode. Thus, the Pt markers are now located in the MgO substrate. 


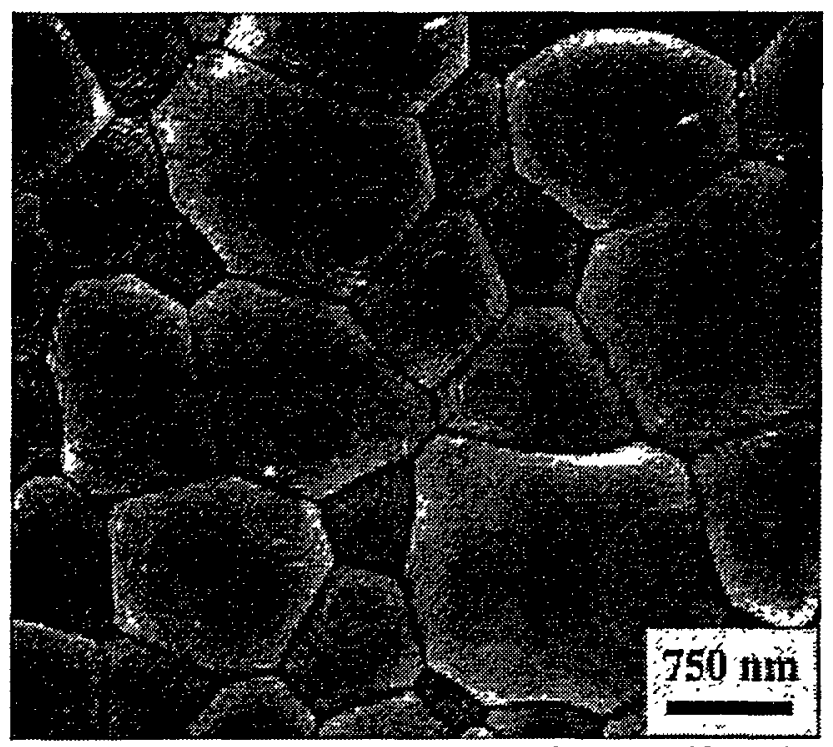

Fig. 1 Plan-view SE image from the $\mathrm{In}_{2} \mathrm{O}_{3}$ layer after annealing. The grain size $(\sim 1 \mu \mathrm{m})$ is comparable to the thickness of the layer.

The reaction product layer is not uniform in the image shown in Fig.2. Some regions of the spinel phase appear to have grown faster compared to the adjacent regions. Closer examination reveals that the faster growth is associated with the grain boundaries in the $\operatorname{In}_{2} \mathrm{O}_{3}$

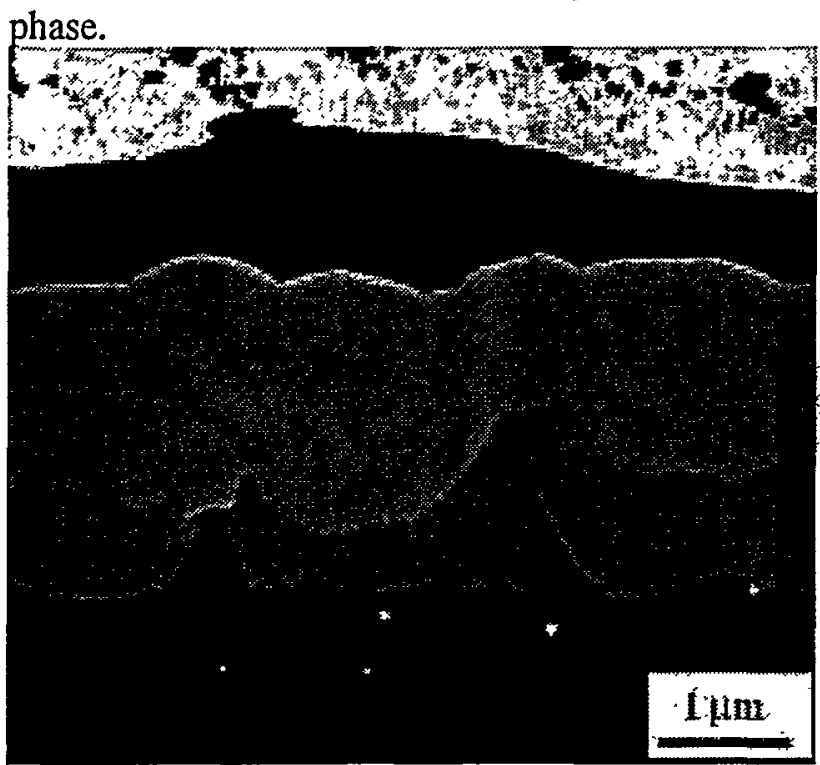

Fig. 2 BSE image from sample A. Only partial reaction to spinel has taken place. The growth of spinel is enhanced along regions where the grain boundaries are present in the $\mathrm{In}_{2} \mathrm{O}_{3}$ layer.

EBSD analysis was carried out on several different regions of the sample. The objective of the EBSD analysis was to confirm the phase identification and obtain orientations of grains of the reaction layer with respect to the MgO substrate and layer. EBSD patterns were recorded from the $\mathrm{MgO}$ substrate and from several grains in the reaction layer and the $\operatorname{In}_{2} \mathrm{O}_{3}$ layer. The layer was identified as $\mathrm{MgIn}_{2} \mathrm{O}_{4}$ by $\mathrm{EDS}$, and the spinel structure was confirmed by EBSD. EBSD patterns from the MgO substrate and the reaction layer are shown in Fig.3(a-b) with some of the zones indexed. Analysis of these patterns indicates that the [001] direction in the $\mathrm{MgO}$ substrate, which is normal to the growth surface, is closely parallel to the [111] direction of the $\mathrm{MgIn}_{2} \mathrm{O}_{4}$ grain within the spinel layer. Additionally, the [1 $\overline{10}$ ] direction of the $\mathrm{MgO}$ substrate is closely parallel to the $[1 \overline{1} 0]$ direction in the spinel grain. Several EBSD patterns were also taken of the $\mathrm{In}_{2} \mathrm{O}_{3}$ layer, however, there appears to be no simple orientation relationship between the $\mathrm{In}_{2} \mathrm{O}_{3}$ and the spinel layer. 

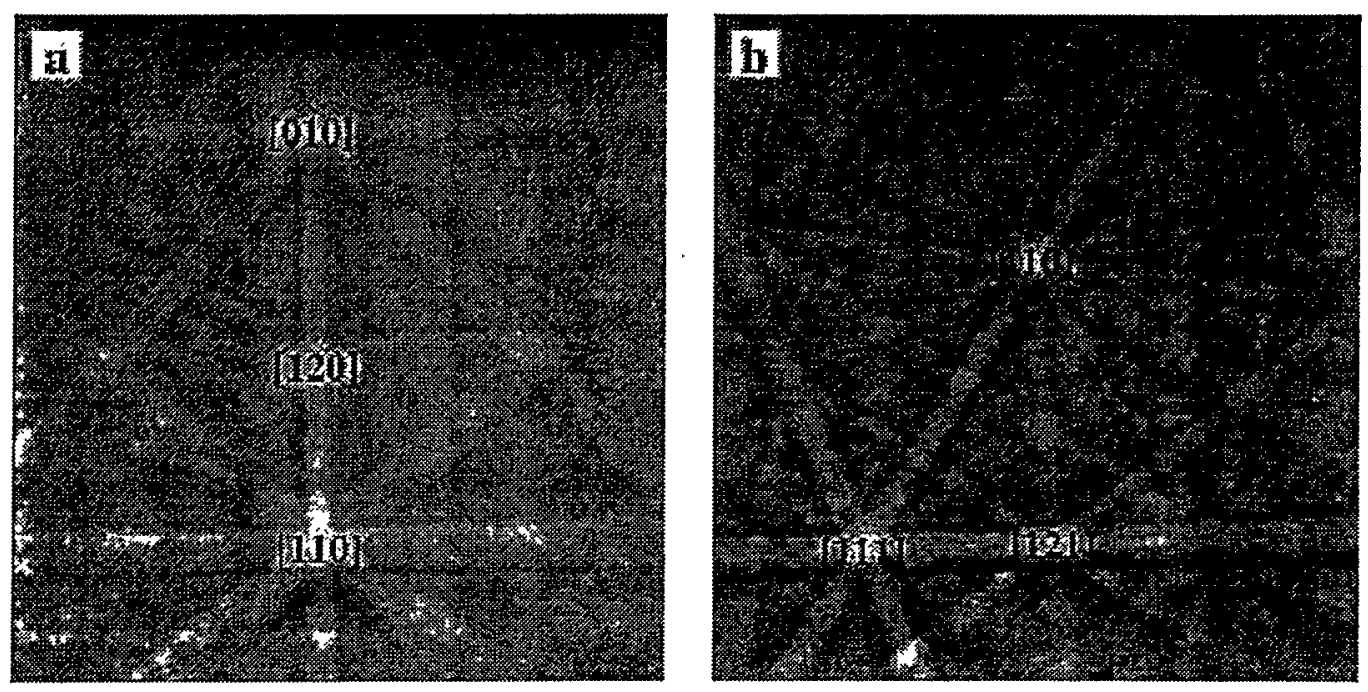

Fig.3 EBSD patterns from the MgO substrate (a) and the spinel layer (b).

- Fig.4 shows a BSE image from sample B, which was annealed at $1350^{\circ} \mathrm{C}$ for 30 mins under an applied field of 200V. Under these conditions, the $\operatorname{In}_{2} \mathrm{O}_{3}$ film has completely reacted to form the spinel. Further annealing results in the transport of $\mathrm{Mg}$ ions across the spinel phase and formation of $\mathrm{MgO}$ on the top of the reaction product. The spinel phase is non-uniform and is composed of spikes along regions where the grain boundaries were located in the $\operatorname{In}_{2} \mathrm{O}_{3}$ layer initially. Again the final products of the reaction were confirmed by EBSD; it was found that the reaction had consumed all of the $\mathrm{In}_{2} \mathrm{O}_{3}$ and that a layer of $\mathrm{MgO}$ was formed on the opposite side of the reaction layer. In order to understand fully the kinetic processes, it is necessary to determine the orientation of the regrown $\mathrm{MgO}$ layer with respect to the substrate as well as the spinel layer. Fig.5(a-b) shows EBSD patterns taken from the substrate and from a grain within the $\mathrm{MgO}$ layer. It is apparent that the orientations are very close. Fig.6 is a stereographic projection which shows the 001-type directions of the substrate and the various regions within the MgO layer. Most of the regions analyzed were very similar in orientation to the substrate.

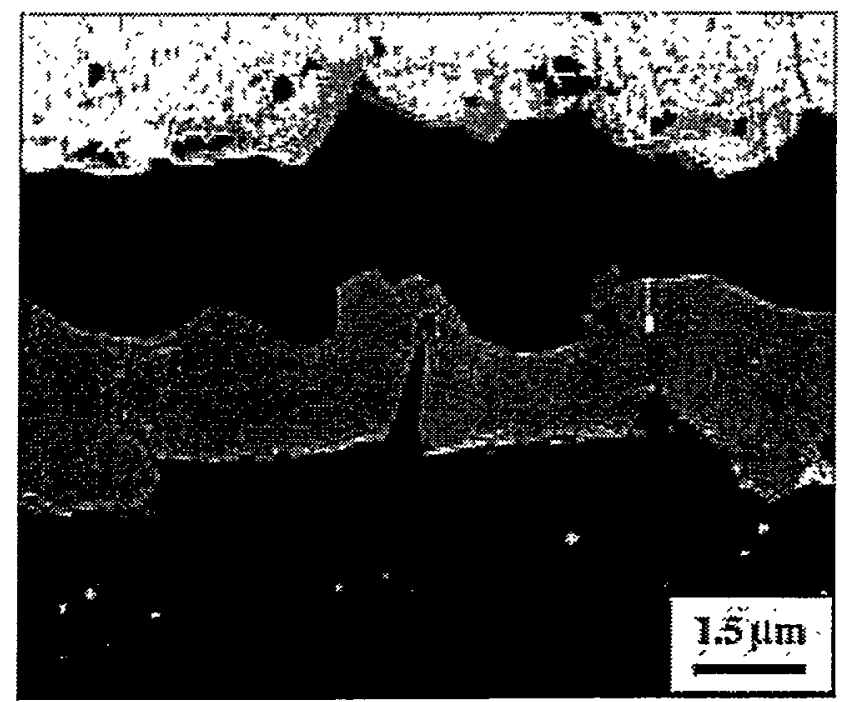

Fig.4 BSE image from sample $B$ indicating that the $\mathrm{In}_{2} \mathrm{O}_{3}$ layer has fully reacted to form the spinel. The overgrown layer of $\mathrm{MgO}$ is seen on top of the spinel layer. The top portion (bright) is from the Pt electrode. 

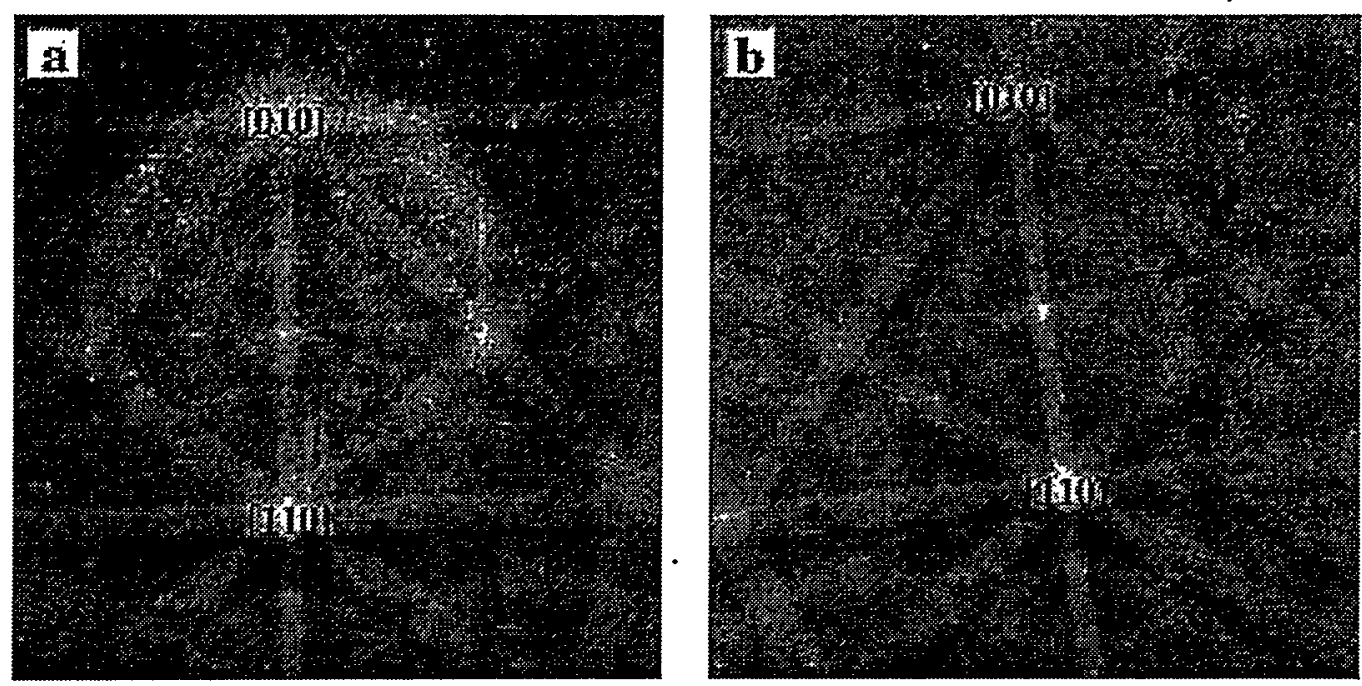

Fig.5 EBSD patterns of the $\mathrm{MgO}$ substrate (a) and the overgrown $\mathrm{MgO}$ layer (b), indicating that they have approximately the same orientation.

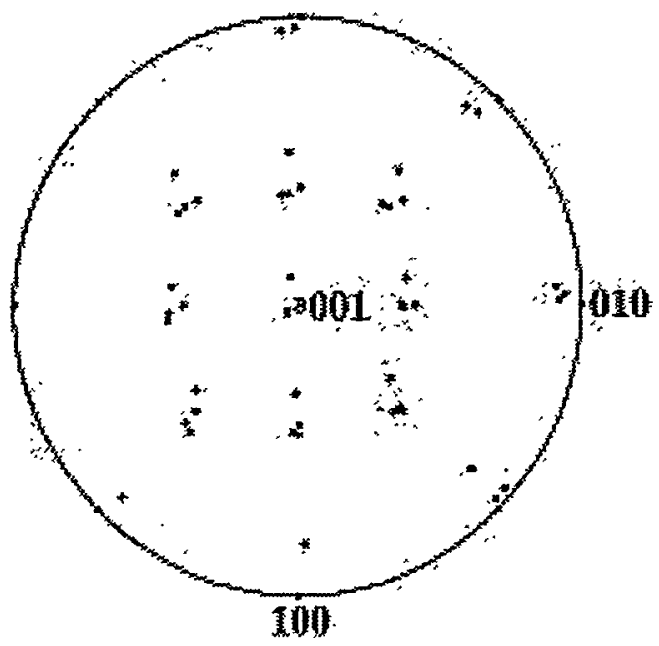

Fig.6 Stereogram showing the 001 projection of the $\mathrm{MgO}$ substrate and near 001 projections from several regions of the overgrown $\mathrm{MgO}$ layer.

\section{CONCLUSIONS}

The results indicate that the morphology during the early stages of growth of the $\mathrm{MgIn}_{2} \mathrm{O}_{4}$ in the electric field is determined by the grain structure of the $\operatorname{In}_{2} \mathrm{O}_{3}$ layer. The reaction front is seen to progress faster at the places where the grain boundaries are present in the $\operatorname{In}_{2} \mathrm{O}_{3}$ layer. Annealing for longer times results in the formation of $\mathrm{MgO}$ on the top of the spinel layer. EBSP analysis provides essential information regarding the crystallography of the reaction.

\section{ACKNOWLEDGMENTS}

This research is supported by the $3 \mathrm{M}$ Harry Heltzer Chair. The authors would like to acknowledge Prof. Stan Erlandsen for access to the FESEM and Chris Frethem for technical assistance. JRM was supported by the United States Department of Energy under contract DE- 
AC04-94AL8500. Sandia is a multiprogram laboratory operated by the Sandia Corporation, a Lockheed Martin company, for the United States Department of Energy.

\section{REFERENCES}

1. H. Schmalzried, Solid State Reactions, Verlag Chemie, Deerfield Beach, Florida, 1981.

2. H. Schmalzried, Chemical Kinetics of Solids, VCH, New York, NY, 1995.

3. P.G. Kotula and C.B. Carter, J. Am. Ceram. Soc. 81, pp. 2869-76 (1998).

4. P.G. Kotula and C.B. Carter, J. Am. Ceram. Soc. 81, pp. $2877-2884$ (1998).

5. P.G. Kotula, M.T. Johnson, and C.B. Carter, Z. Phys. Chem. 206, pp. 73-99 (1998).

6. P.G. Kotula and C.B. Carter, Phys. Rev. Lett. 77, pp. $3367-3370$ (1996).

7. M.T. Johnson, H. Schmalzried, and C.B. Carter, Solid State Ionics 101-103, pp. 1327-1333 (1997).

8. M.T. Johnson, S.R. Gilliss, and C.B. Carter, Microscopy \& Microanalysis 4, pp. 158-163 (1998).

9. M.T. Johnson and C.B. Carter, Phil Mag Lett. in press, pp. (1999).

10. P.G. Kotula, D.D. Erickson, and C.B. Carter in The Use of Thin Film Substrates to Study Enhanced Solid-State Transformations, edited by (Mat. Res. Soc. Symp. Proc., 319, , pp. 57-62.

11. M.T. Johnson, C.B. Carter, and J. Michael, J. Am. Ceram. Soc. 82, pp. 1644-1646 (1999).

12. R.P. Goehner and J.R. Michael, Journal of Research of the National Institute of Standards \& Technology 101, pp. 301-8 (1996). 